\title{
Evaluation of king oyster mushrooms strains (Pleurotus eryngii) on selective lignin degradation in wheat straw: An update
}

A.S.M. Sonnenberg, M.H.M. Visser, B. Lavrijssen, J.W. Cone \& P.M. Hendrickx

WageningenUR, Plant Breeding

This study was carried out by Wageningen UR (University \& Research centre) and was commissioned and financed by the Dutch Ministry of Economic Affairs, Productschap Tuinbouw, C4C Holding and Dyadic.

Wageningen UR is the collaboration of Wageningen University and the foundation Stichting Dienst Landbouwkundig Onderzoek.

Wageningen, December 2016

DOI: $10.18174 / 401881$

TKI T\&U: KV 1310-032

PPO/PRI report 2016-4 
A.S.M. Sonnenberg, M.H.M. Visser \& P.M. Hendrickx, 2015. Evaluation of king oyster mushrooms strains (Pleurotus eryngii) on selective lignin degradation in wheat straw; . Wageningen, the foundation Stichting Dienst Landbouwkundig Onderzoek. Research Institute Praktijkonderzoek Plant \& Omgeving / Plant Research International, Wageningen UR (University \& Research centre), PPO/PRI report 2016-4.

Keywords: Agaricus bisporus, compost, biological efficiency

(C) 2015 Wageningen, Stichting Dienst Landbouwkundig Onderzoek, Research Institute Praktijkonderzoek Plant \& Omgeving/Plant Research International, P.O. Box 16, 6700 AA Wageningen, The Netherlands; T +31 (0)317 4807 00; www.wageningenur.nl/en/XX

Chamber of Commerce no. 09098104 te Arnhem

VAT NL no. 8065.11.618.B01

Stichting Dienst Landbouwkundig Onderzoek (DLO Foundation). All rights reserved. No part of this publication may be reproduced, stored in an automated database, or transmitted, in any form or by any means, whether electronically, mechanically, through photocopying, recording or otherwise, without the prior written consent of the DLO Foundation.

DLO is not liable for any adverse consequences resulting from the use of data from this publication.

PPO/PRI report 2016-4 


\section{Contents}

\section{Table of Contents}

\section{Contents 3}

1

Introduction

$\begin{array}{ll}\text { Results } & 7\end{array}$

3.1 Genotyping the WUR-PB collection of Pleurotus eryngii species-complex. 7

$\begin{array}{lll}3.2 & \text { Genotyping the } L \text {. edodes collection } & 10\end{array}$

3.3 Degradation of Miscanthus by two $P$. eryngii strains 10

3.4 Degradation of wheat straw by a selection of $20 P$. eryngii strains $\quad 11$

3.5 Influence of fungal pretreatment (P. eryngii) on digestibility of wheat straw 13

4

Conclusion

15

5

References

16

6

Appendix

17 


\section{Introduction}

The king oyster mushroom (Pleurotus eryngii) is a delicious mushroom with a large market potential (personnel communication Banken Champignons B.V.). Most fresh products in Europe are imported from the Republic of Korea and an improved production system will help to increase the local production. This also includes the use of varieties with an improved yield and quality. Next to the production of edible mushrooms, this species can also be used to upgrade lignocellulose materials. The king oyster mushroom is a white rot fungus that can degrade lignin selectively in lignocellulosic materials (degradation of lignin while hardly any cellulose is degraded; (Tuyen et al. 2013). This will facilitate the access to the polysaccharide cellulose, a source for the generation of bioenergy and bioplastics. In addition, the selective removal of lignin with a white rot fungus increases the digestibility for ruminants ((Kuijk 2016)) and when for this purpose white rot fungi are used that produce edible mushrooms, the treated substrate is generally considered as safe (GRAS) and thus suitable as an animal feedstock. These arguments also accounts for the shiitake mushroom (Lentinula edodes). Shiitake is less produced in the Netherlands but has proven to be an interesting species for selective removal of lignin in lignocellulose biomass ((Kuijk 2016).

Most research done on selective degradation of lignin by white rot fungi has been directed to screening of fungal species and substrate combinations. Hardly any research has been done to evaluate the performance of strains within one species. Pleurotus eryngii forms a species-complex of fungi growing on roots and lower stem residues of Apiaceae (umbellifers) plants (Zervakis et al. 2014) and found in many part is the world. The fungal collection of Wageningen UR Plant Breeding (WUR-PB) contains a large number (156) of strains assigned to this complex and a proper genotyping of these strains have not been done so far. The collection also contains a large number of shiitake strains (99) which have been collected in the last 40 years by exchanging strains with other collections, sampling from commercial spawn or gifts from third persons. The genetic variation within this species is also not known well. The project has thus first evaluated the genetic diversity within these two species in order to make a selection that represent the genetic variation for each species. The selection of $P$. eryngii has subsequently been evaluated for the selective degradation of lignin in Miscanthus and in wheat straw. The fibre content of the treated wheat straw has been analysed and the effect of this treatment on the digestibility by ruminants by using a in vitro gas production model (IVGP).

A small sample of $3 \mathrm{~L}$. edodes strains have been pre-tested on 2 Miscanthus varieties that differ in lignin content. This is done before we will evaluate a large set of strains on lignin degradation in Miscanthus. A good performance (high lignin degradation in combination with a low cellulose degradation) makes a strain useful for upgrading lignocellulose but might also benefit the production of fruiting bodies. Degradation of lignin enhances the access to polysaccharides and can thus potentially improve also mushroom yield. 


\section{Materials \& Methods}

All strains from the Pleurotus eryngii (156 strains) and Lentinula edodes have been grown on MMP medium as described before (Sonnenberg et al. 1996)and freeze dried mycelium was used to extract DNA as described in Sonnenberg et al, 2016 (submitted). (Sonnenberg et al. 2016). The DNA samples of the $P$. eryngii were subsequently used a low complexity sequencing method. The SNP detected were combined in sequence strings and aligned with CLC Main Workbench version 7.6.2. The alignments were exported as a NWK files and used to generate dendrograms (Archeopteryx version 0.972; (Han and Zmasek 2009)). The L. edodes strains were genotypes with AFLP as described in Terashima et al.(Terashima et al. 2002).

Each strain and time point for $P$. eryngii on wheat straw was done in duplicate using plastic trays (http://www.microbox-container.com/) filled with ca. $250 \mathrm{gr}$ wheat straw.

Three different Miscanthus varieties varying in lignin content and one wheat straw variety were used. The fungal treatment of these materials was done as described in Kuijk et al. (2016). Fibre analysis was performed according to the method of Van Soest et al. (1991) (Van Soest et al. 1991)and described in more details in Kuijk et al. (Kuijk 2016).

The effect of fungal pretreatment on the digestibility of wheat straw was tested as described by Kuijk et al 2016 (Kuijk 2016). In short, samples were freeze dried after fungal pretreatment and used in a glass vial filled with a sample of ruminant fluid from a cow and flushed with N2 gas to generate an anaerobic environment. The vials were incubated at $37 \mathrm{oC}$ and gas productions were measured during 72 hours and used to calculate the increase in gas productions by the fungal treatment as a measure for the increase in ruminant digestibility. 


\section{Results}

\subsection{Genotyping the WUR-PB collection of Pleurotus eryngii species-complex.}

Of the 156 strains, 140 generated DNA of sufficient quality to be used for genotyping by a low comoplexity sequence mthodology. This method generated sequences of sufficient quality for 378 SNP ( $\leq 20 \%$ missing data per locus). The collection contains a large set of strains isolated from the wild in Iran (Behnamian et al., 2010) (Behnamian et al. 2010). The genotyping methodology could discriminate strains sampled from different geographic locations within the country. Three groups are seen within the Chamahal Bakhtiari region and two groups within the Kourdistan Province region. One of each of these groups and the commercially cultivated varieties show a close relationship (figure 1). Two wild strains collected in the Chamahal Bakhtiari region fall within the group of commercially grown varieties. This might indicate that the commercial varieties originate from this region or represent escapes from cultivated varieties. One of the Kourdistan group is only found on Ferula ovina or $F$. haussknechtii host plant whereas strains from other groups are found on different Umbellifer species (in addition on Smyrniopsis aucheri, Kellusia oderatissima, Ferula assa-foetida, Prangos ferulacea). A dendrogram of the complete collection of Plant Breeding showed a clear grouping of strains more or less according to what was expected based on data available for these strains. The strains of $P$. eryngii that are used to generate edible mushrooms in Europe and the USA

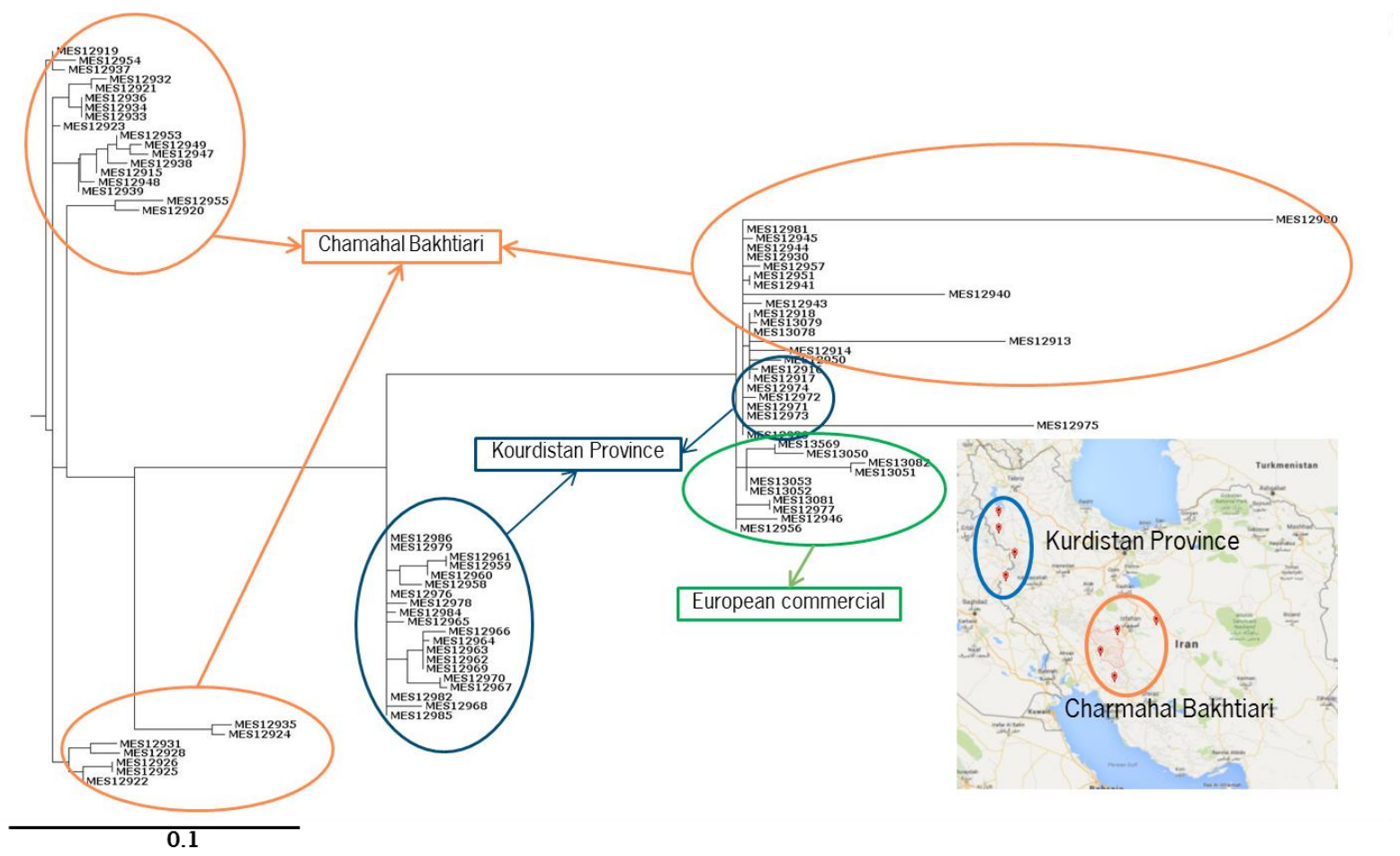

Figure 1. Dedrogram showing the genetic relationship of strains within the species-complex Pleurotus eryngii. Strains were collected in two regions of Iran (Behnamian et al., 2010). Genotyping was done with GBS.

cluster in two groups with a low genetic variation within each group (Figure 2). Although no details are available of their origin, such a clustering was expected since not much breeding is done within the mushroom industry and new varieties are generally not generated by outcrossing but by the screening of multispore cultures. Growers also tend to use the same (and best) variety. The GBS also identified two groups originating from China. Unfortunately, no data on the location of collection are available. One set of these Chinese strains group with a cluster isolated in the Kourdistan region in Iran but are distinct from this group. The other group is representing likely the Chinese $P$. eryngii subsp. tuoliensis (Wei Gao, personal communication and Kawai et al, 2008 (Kawai et al. 2008)), a subspecies reported 
to have evolved independently in China. Finally, a group was identified collected in Sicily (Italy) and reported to represent possibly P. eryngii var. elaeoselini (Venturella et al 2000) (Venturella et al. 2000). The genetic variation in the collection shows clearly the potentials for breeding, although an evaluation of variation in useful phenotypes have to be done.

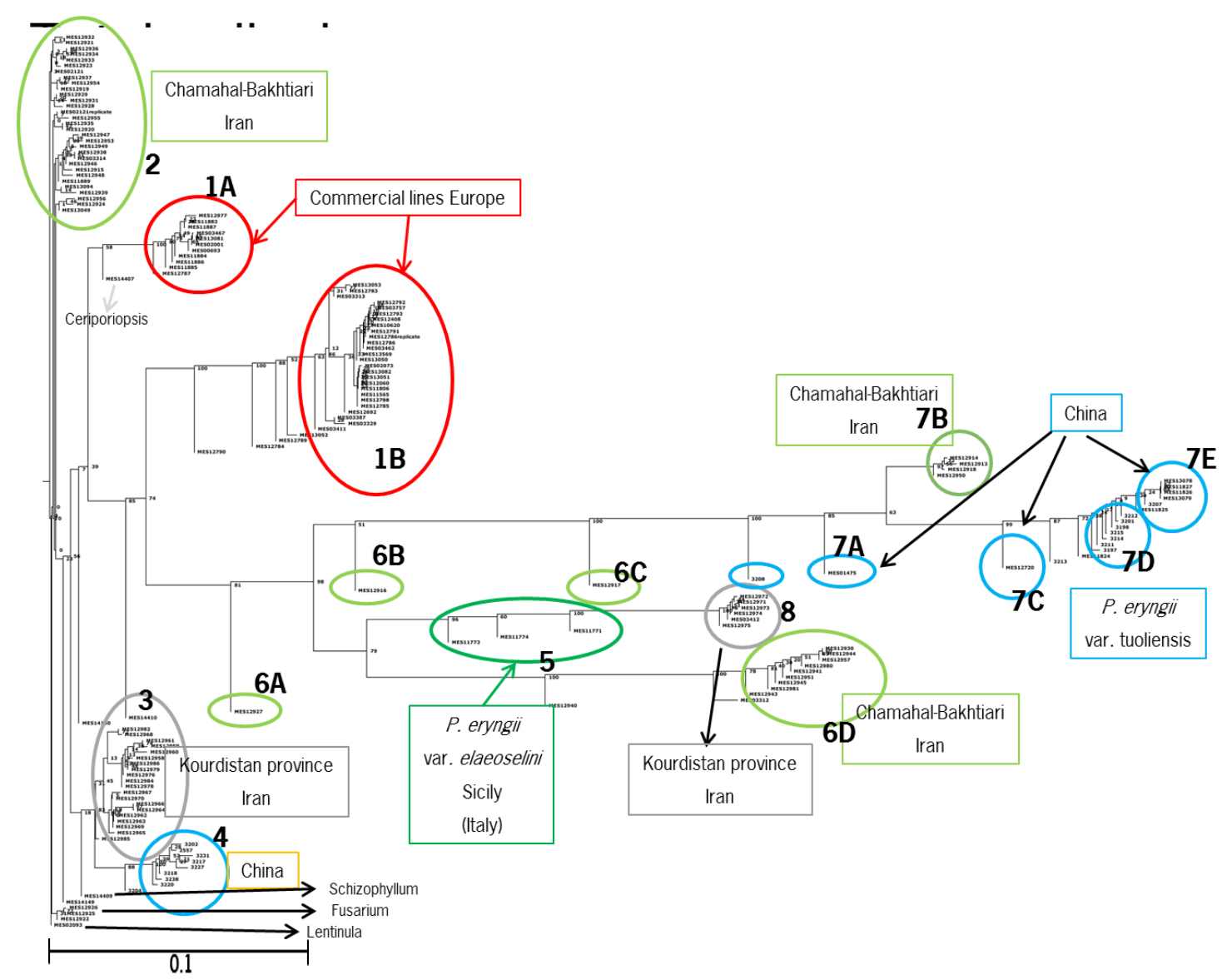

Figure 2. Dedrogram showing the genetic relationship of all strains of the Plant Breeding collection within the species-complex Pleurotus eryngii. Genotyping was done with GBS. Strains collected in the same country or region are encircled in the same colour. The different phylogenetic groups are numbered and from each group 2 strains were selected for selective degradation lignin in wheat straw. 



\subsection{Genotyping the $L$. edodes collection}

Of the 99 strains of $L$. edodes present in the collection, 87 were genotyped. The missing strains did not grow very well and were omitted from genotyping due to the limited time for genotyping. The AFLP analysis revealed a large genetic variation between strains of this species. In most cultivars of edible mushrooms such as Pleurotus ostreatus (grey oyster mushroom), Pleurotus eryngii and Agaricus bisporus (button mushrooms), commercial lines usually cluster in groups with a low genetic variation. The commercial varieties of shiitake, however, are scattered over all groups indicating a large genetic variation in cultivars. One group stands a bit out of the dendrogram and a ITS sequencing was done. This group also contained one strain as an outgroup (Pleurotus eryngii). To verify that these strains were indeed $L$. edodes, an ITS sequencing was done on these strains. Only one strain (MES 02017) appeared to be a different species: Bjerkandera adusta. All others are indeed $L$. edodes. This emphasis the large genetic variation of strains within this species.

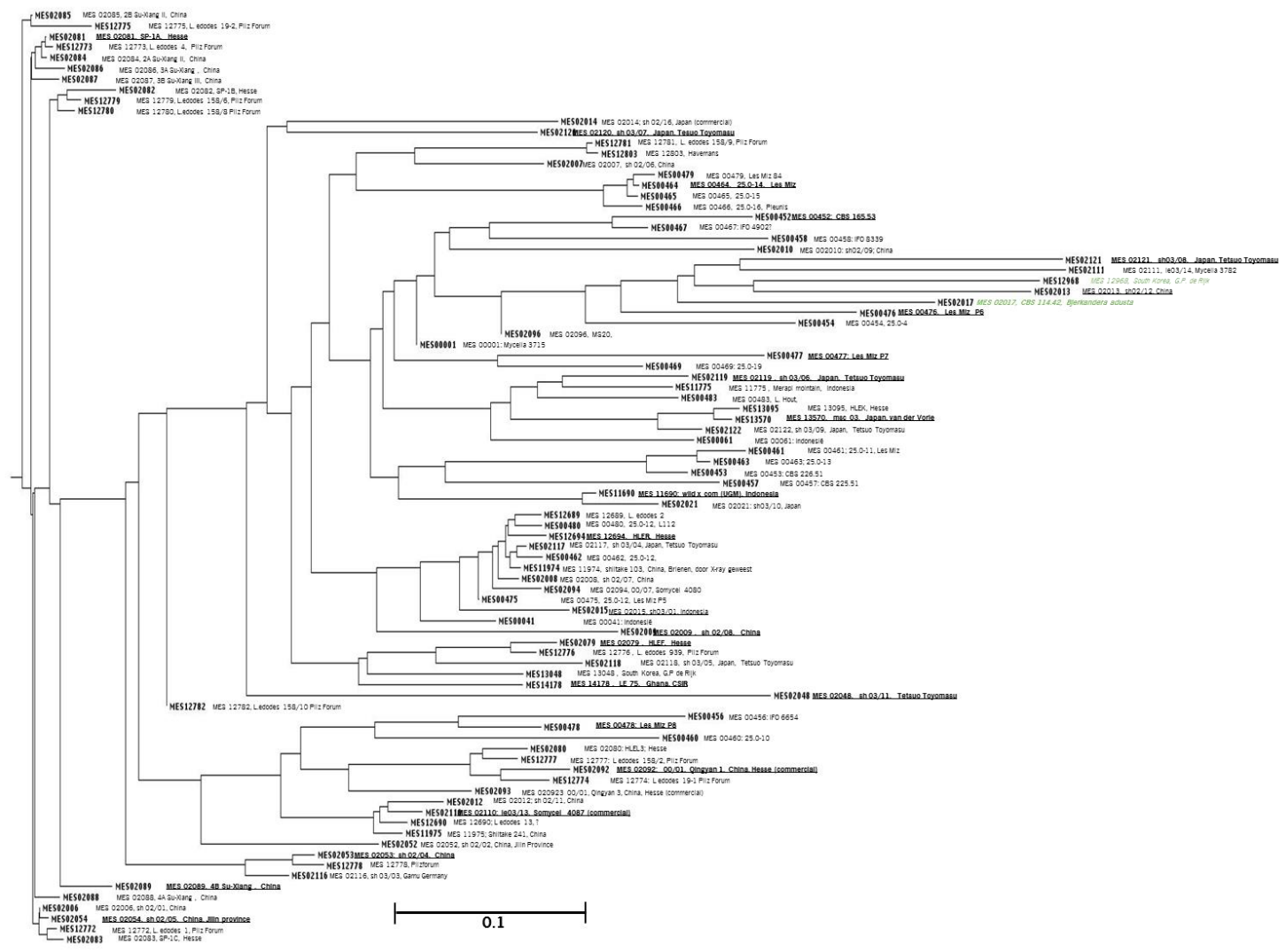

Figure 3. Dendrogram of 87 Lentinula edodes strains from the Plant Breeding collection using AFLP. The 2 green strains represent other species (Pleurotus eryngii and Bjerkandera adjusta).

\subsection{Degradation of Miscanthus by two P. eryngii strains}

In the initial proposal we intended to test a selection of strains of $P$. eryngii on 2 different varieties of Miscanthus with low and high lignin content. In another project, however, it appeared that the strain of $P$. eryngii tested did not grow well on Miscanthus and showed hardly degradation of lignin. As a preliminary test we, therefore, selected 2 strains and analysed the degradation of Miscanthus at two time points, after 4 and 7 weeks. Both strains growth very thin on the substrate and the fibre analysis showed now significant degradation of the different fibres (figure 3). For the subsequent experiments we switch therefore to wheat straw since previous experiments have shown that $P$. eryngii can grow well on this substrate. 


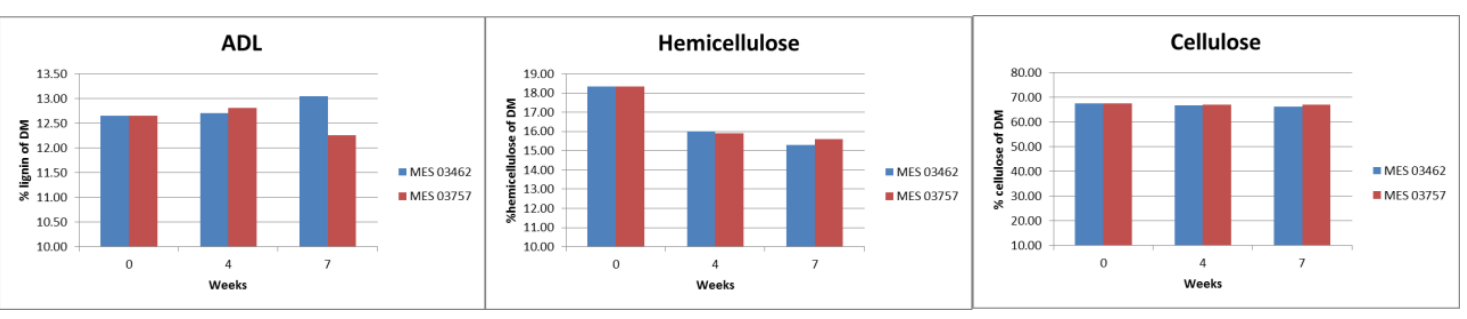

Figure 4. Degradation of fibre components by two P. eryngii strains in wheat straw. The fractions of ADL (lignin), hemicellulose (NDF-ADF) and cellulose (ADF-ADL) of the total dry matter are plotted.

\subsection{Degradation of wheat straw by a selection of $20 P$. eryngii strains}

After the assessment of the genetic variation of the $P$. eryngii strains within the Plant Breeding collection, a selection was made representing each of the phylogenetic groups (table 1). For each of these 20 strain, six containers (each with ca 250 gram of sterilized wheat straw) was inoculated with spawn. At each time point after inoculation (3, 6 and 9 weeks), 2 containers were freeze dried and used to analyse fibre content (ANKOM based on van Soest et al., 1991). The dry weight of each container was also measured for all samples. These data, however, varied considerably and could not be used to make a good mass balance. The data are thus represented as fractions of dry matter. There are significant differences in fibre content of wheat straw treated with different $P$. eryngii strain. These are

\begin{tabular}{llc} 
& Strain & Phylogenetic Group \\
\cline { 2 - 2 } Table 1. Selection of & MES 12948 & 2 \\
strains of the $P$. & MES 12937 & 2 \\
eryngii collection & MES 12962 & 3 \\
used for the selective & MES 12961 & 3 \\
degradation of lignin & MES 11773 & 5 \\
in wheat straw. The & MES 11774 & 5 \\
selection was made & MES 12975 & 8 \\
in such a way that & MES 12972 & 8 \\
each group (figure 1) & MES 12787 & $1 \mathrm{~A}$ \\
is represented. & MES 03467 & $1 \mathrm{~A}$ \\
& MES 03757 & $1 \mathrm{~B}$ \\
& MES 11565 & $1 \mathrm{~B}$ \\
& MES 12927 & $6 \mathrm{~A}$ \\
& MES 12917 & $6 \mathrm{C}$ \\
& MES 12980 & $6 \mathrm{D}$ \\
& MES 12943 & $6 \mathrm{D}$ \\
& MES 12913 & $7 \mathrm{~B}$ \\
& MES 12720 & $7 \mathrm{C}$ \\
& MES 13078 & $7 \mathrm{E}$ \\
& MES 11825 & $7 \mathrm{E}$
\end{tabular}

particularly evident after 9 weeks of incubation (figure 5). A positive correlation was seen between lignin and hemicellulose content whereas a negative correlation was found between lignin and cellulose content (figure 6). This indicates a selective lignin removal with respect to cellulose and thus an increase in cellulose content after 9 weeks of incubation. This usually gives rise to an crease in digestibility for ruminants (Tuyen et al. 2012)and an improvement in the extend of saccharification with enzymes (Kuijk et al., in preparation). The analysis for digestibility and saccharification are in progress. The best 6 strains (causing the lowest lignin content in wheat straw after 9 weeks) are wild isolates derived from Iran from groups that show a large genetic variation (appendix figure A2). The strains with the lowest performance (high lignin content after 9 weeks incubation) are isolates from the wild from Sicily (Italy) and China, the latter putative var. tuoliensis. This latter group of fungi usually need a long time for a complete colonization of substrate and a cold period (14 days at $5-7^{\circ} \mathrm{C}$ ) before fructification is induced at $15-17^{\circ} \mathrm{C}$ (Kawai et al., 2008). The strains with an intermediate performance in lignin degradation are mostly represented by the commercial lines. The differences between the best and worst performing strains are evident (table 2). Statistical analysis are given in the Appendix (Table A1).

$\begin{array}{cccc}\text { Strain } & \text { ADL } & \text { Hemicel. } & \text { Cellulose } \\ \text { MES12975 } & 42 \% & -38 \% & 5 \% \\ \text { MES11774 } & 18 \% & -29 \% & 1 \%\end{array}$

Table 2. Change in fibre content between the two extremes strains in lignin degradation. 


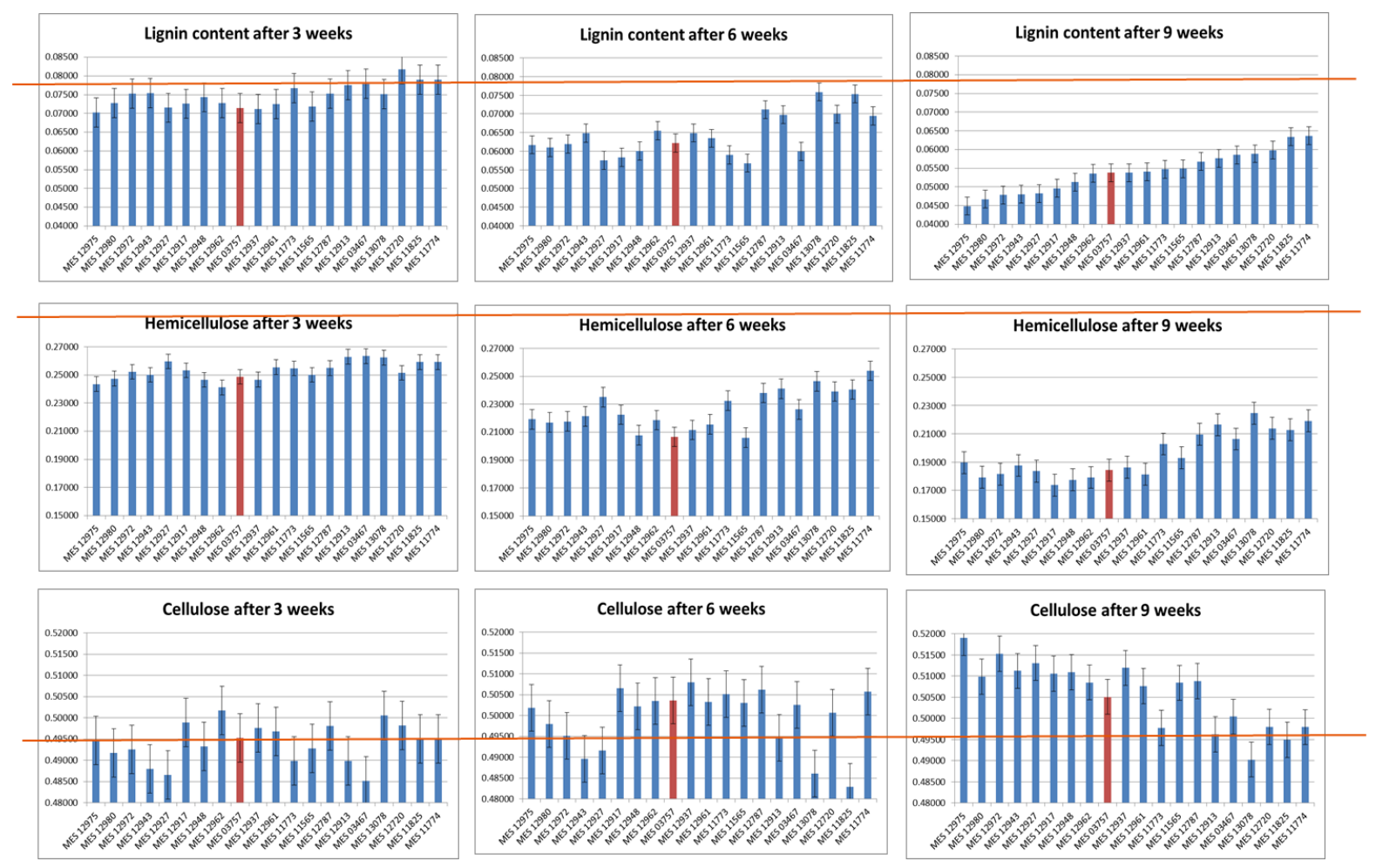

Figure 5. The fibre constitution (fraction of dry weight) of wheat straw incubated for 3, 6 or 9 weeks with 20 different strains of $P$. eryngii. Lignin is expressed as ADL, hemicellulose as NDF-ADF and cellulose as ADF-ADL. The strains are sorted on lignin content after 9 weeks of incubation. The orange line in each graph indicates the content of each fibre in non-inoculated wheat straw. The strain with the red bar represents a strain that is used before in previous work (Tuyen et al., 2012 and 2013).
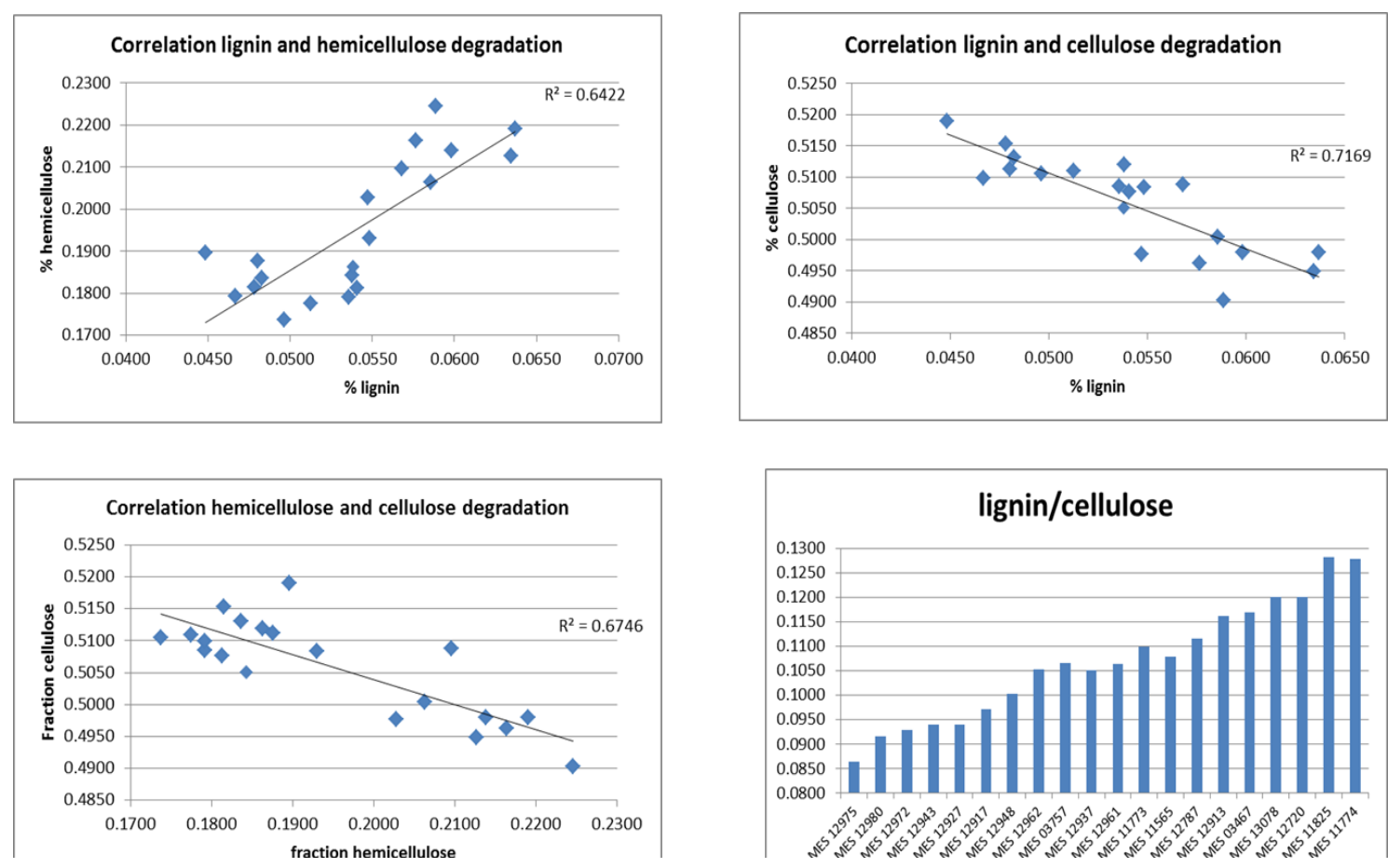

Figure 6. Correlations between changes in content of different fibre fraction after treatment of 9 weeks with 20 different strains of $P$. eryngii. A positive correlation between lignin and hemicellulose content, a negative correlation between lignin and cellulose content and as a result also a negative correlation between hemicellulose and cellulose content. In the last figure (bottom right), strains were sorted on the lignin content of wheat straw after 9 weeks of incubation (as in figure 4). The ratio between lignin and cellulose correlates then almost perfectly

12 | Kies een item.-rapport Xxxx 


\subsection{Influence of fungal pretreatment ( $P$. eryngii) on digestibility of wheat straw}

To test the influence of the fungal treatment on the digestibility of wheat straw by ruminant, the in vitro gas production (IVGP) system was used as described in M\&M. A large variation was seen in the

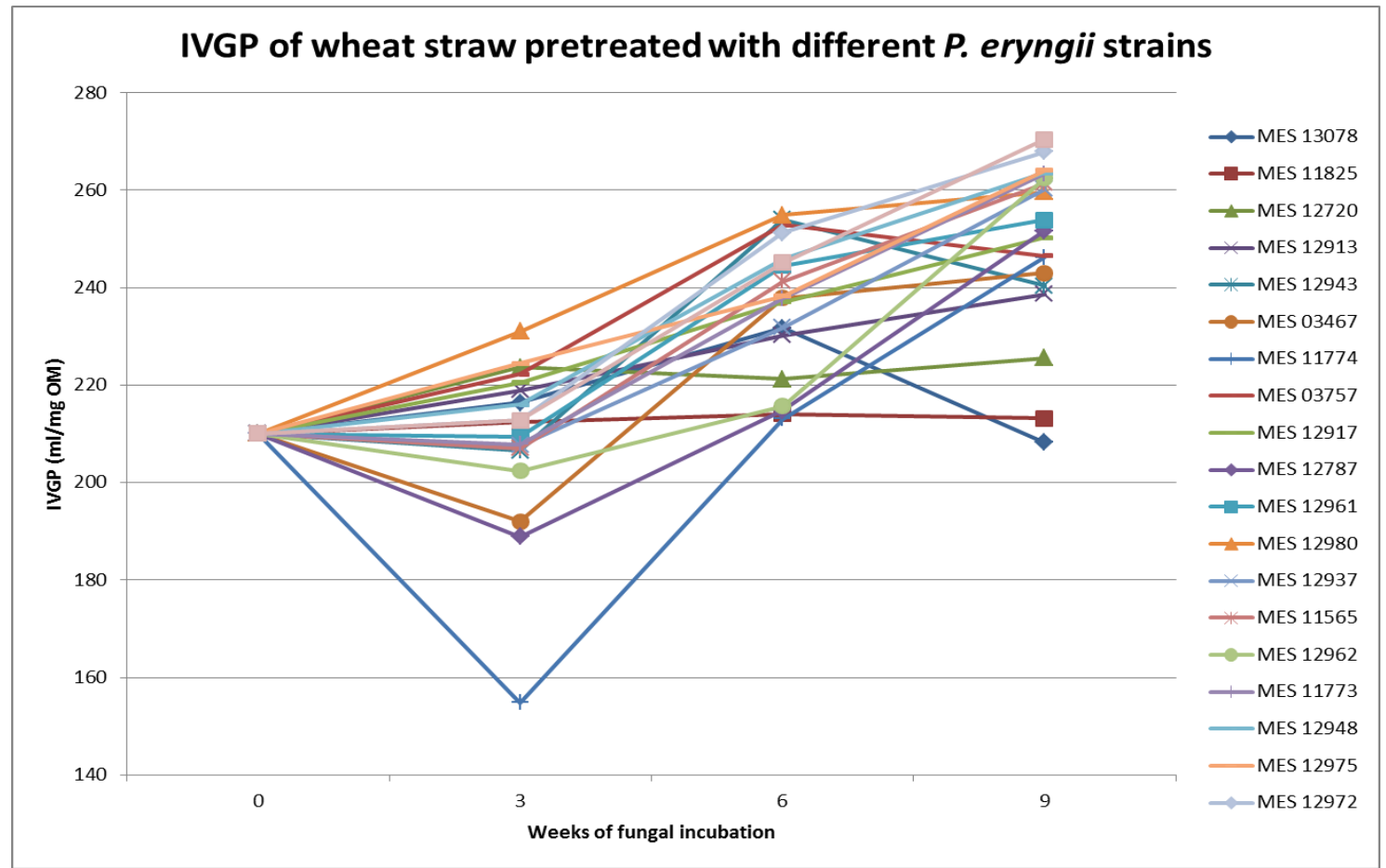

Figure 7. In vitro gas production (accumulation after 72 incubation with ruminant fluid) of fungal treated wheat straw. Samples were incubated for 3, 6 or 9 weeks with 20 different strains of $P$. eryngii.
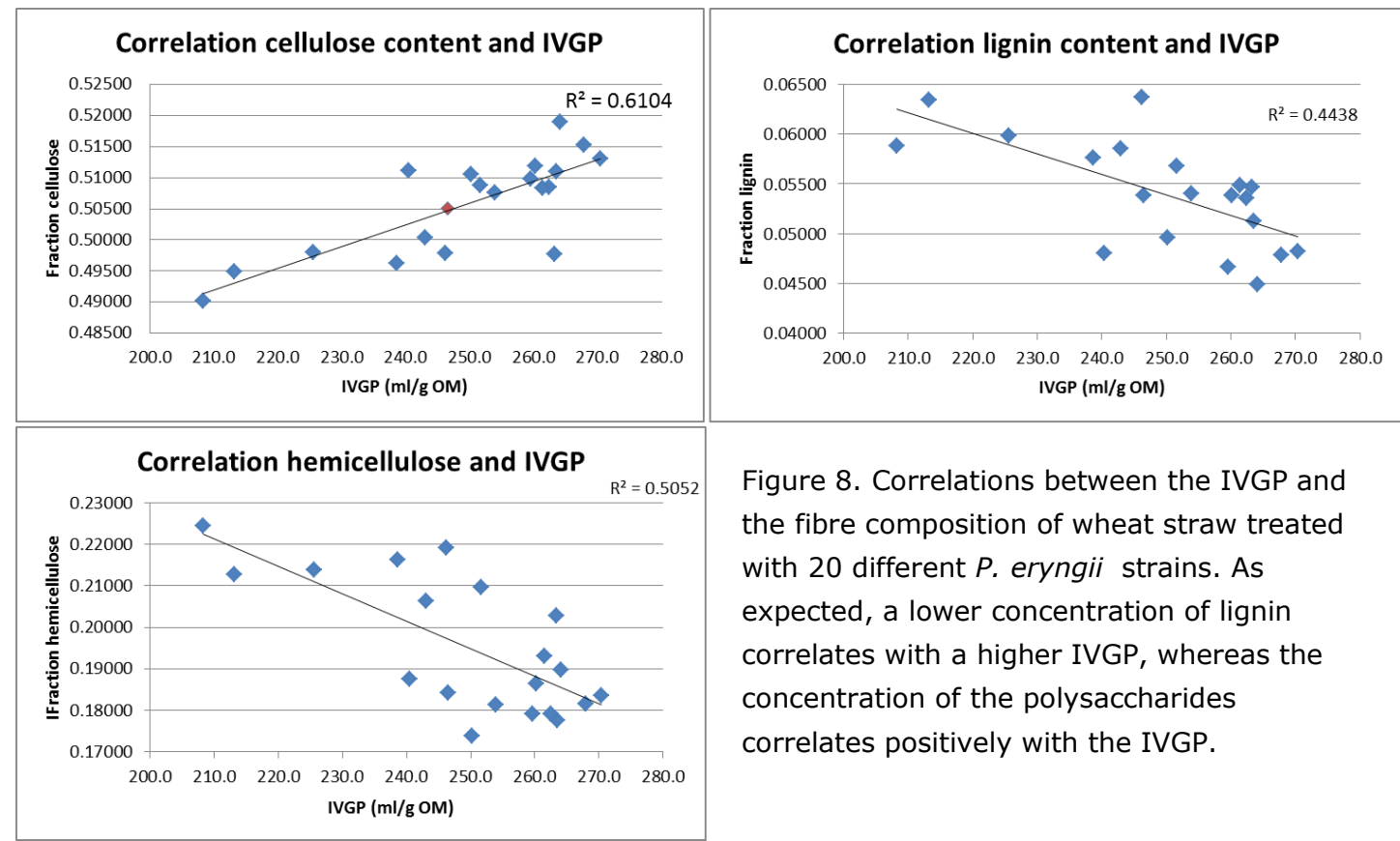

Figure 8. Correlations between the IVGP and the fibre composition of wheat straw treated with 20 different $P$. eryngii strains. As expected, a lower concentration of lignin correlates with a higher IVGP, whereas the concentration of the polysaccharides correlates positively with the IVGP.

gas production after 3, 6 and 9 weeks of fungal treatment. After 9 weeks of pretreatment some strain did not improve gas production at all whereas some increased gas production with almost $30 \%$. The variation in duplicates were large resulting in many treatments not differing significantly (Table $2 \mathrm{~A}$ ). As expected, the differences in gas production correlates with the fibre content of the treated wheat straw. The lignin content of the wheat straw is negatively correlated with the IVGP. That means that removal of lignin enhances the accessibility of the polysaccharides. As expected, we found a positive correlation between the cellulose content and IVGP. The higher the cellulose content the higher is the IVGP. That accounts also for the content of hemicellulose. The pretreatment might have a multiple 
effect: removing lignin and making polysaccharides more available, increasing the concentration of polysaccharides and enhancing the degradability of crystalline cellulose. The latter might be the result of the unspecific action of radical molecules generated by the fungus resulting not only in a degradation of lignin but also etching crystalline cellulose enabling endocellulase to attack crystalline cellulose.

\subsection{Three Lentinula edodes strains on two Miscanthus varieties}

As a preparation on an extended test of shiitake strains on Miscanthus, two Miscanthus varieties were incubated with 3 different $L$. edodes strains. The first variety (E192) has a lignin content of approximately $9.3 \%$ and the variety $\mathrm{E} 199$ has a lignin content of ca. 7.4\%. Incubation periods were 4 and 7 weeks and each treatment carried out in duplicate. As seen with $P$. eryngii on wheat straw, here also a decrease in lignin content accompanies a decrease in hemicellulose and an increase in cellulose content (figure 7). There is a significant decrease in lignin content with all shiitake strains with both Miscanthus varieties after 7 weeks of incubation (Table 3). Although statistical analysis is

\begin{tabular}{|c|c|c|c|}
\hline & \multicolumn{3}{|c|}{ Change after 7 weeks incubation } \\
\hline & ADL & Hemicellulose & Cellulose \\
\hline \multicolumn{4}{|c|}{ Miscanthus E192 } \\
\hline MES 02079 & $-21.5 \%$ & $-43.1 \%$ & $0.9 \%$ \\
\hline MES 02121 & $-25.5 \%$ & $-47.4 \%$ & $6.1 \%$ \\
\hline MES 11910 & $-26.1 \%$ & $-43.4 \%$ & $4.2 \%$ \\
\hline \multicolumn{4}{|c|}{ Miscanthus E199 } \\
\hline MES 02079 & $-20.1 \%$ & $-44.3 \%$ & $0.9 \%$ \\
\hline MES 02121 & $-31.5 \%$ & $-45.4 \%$ & $5.8 \%$ \\
\hline MES 11910 & $-29.4 \%$ & $-48.0 \%$ & $4.3 \%$ \\
\hline
\end{tabular}
difficult to perform on samples changing in time, it seems that strain MES 02079 performs less than the other two strains indicating that there is an effect of the genotype of the shiitake strain. The effect of the lignin content in the extend of lignin degradation and enrichment in cellulose seems negligible. It is expected that changes will be larges when the incubation period is extended to 9 weeks (Kuijk 2016).

Table 3. Percentage change in fibre content by 3

different shiitake strains on 2 varieties of

Miscanthus.
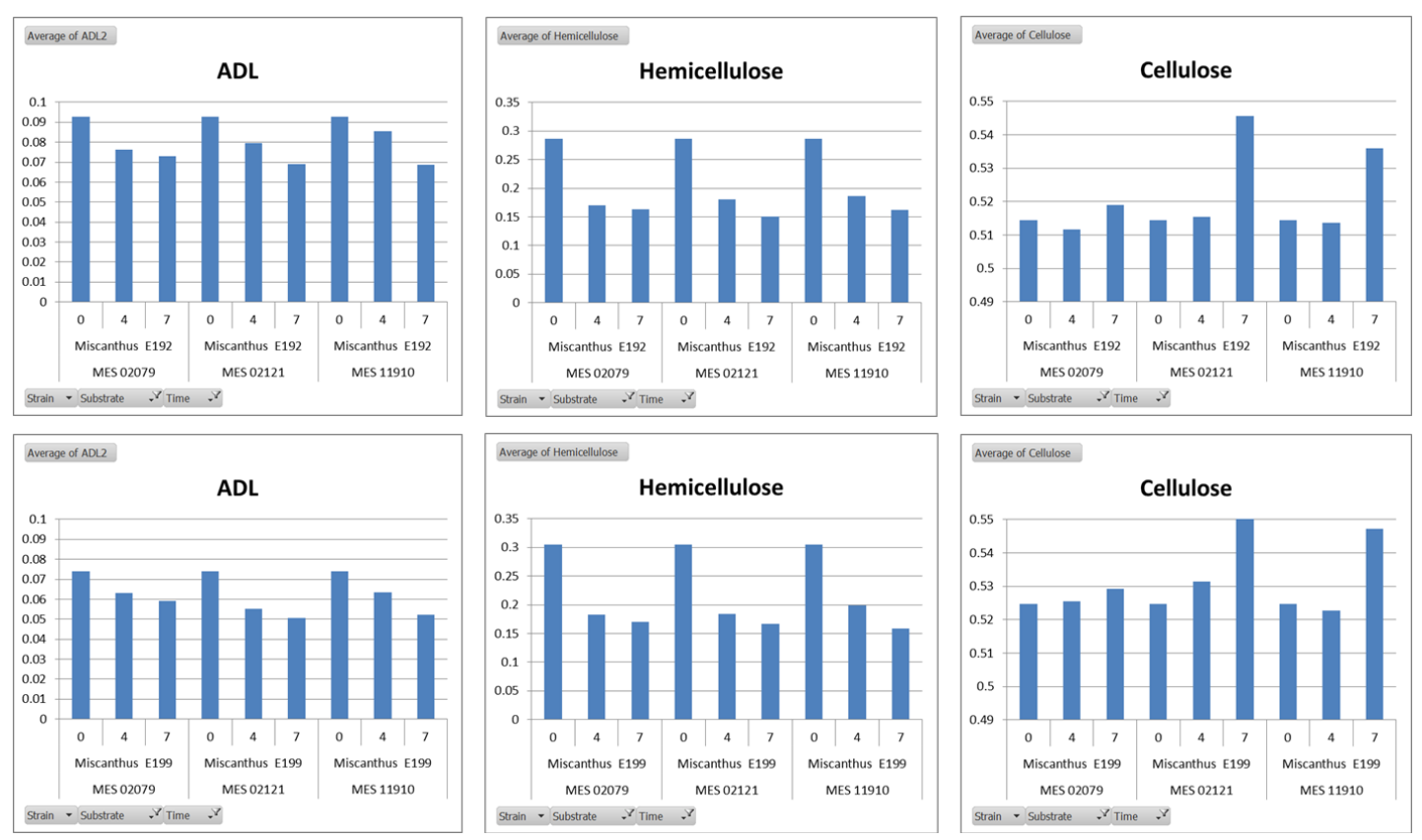

Figure 7. Change in fibre content of two Miscanthus varieties after treatment with three different shiitake strains for 0,4 and 7 weeks. 


\section{Conclusion}

The strains of Pleurotus eryngii and Lentinula edodes of the plant breeding collection represent a large genetic variation. The strains of $P$. eryngii cluster in groups that show within each group a limited variation. That is partly due to the sampling in small areas in Iran and due to the fact that the commercial varieties are very similar. The latter is common practise in the mushroom industry where breeding is hardly done and when applied, usually selections are made from multispore cultures that obviously will lead to similar genotypes. In contrast, the genetic variation within the Lentinula edodes collection is large. Also the commercial lines used are scattered over the whole dendrogram. This is consistent with the finding that yield, mushroom shape and qualities are also very different between cultivars.

The king oyster mushroom is performing less in selective lignin degradation than other white rot fungi but the genetic variation and the variation in lignin degradation indicates that this species can be improved by breeding. Such breeding program might also improve the utilisation and thus yields in mushroom production. It might also be interesting to grow this species on other lignocellulose materials and see if it performs better on these sources. 


\section{$5 \quad$ References}

Behnamian M, Mohammadi SA, Sonnenberg ASM, Goltapeh EM, Hendrickx PM (2010) Genetic diversity and population structure of Iranian wild Pleurotus eryngii species-complex strains revealed by URP-PCR markers. Journal of Food, Agriculture \& Environment 8(3\&4):1203-1207

Han MV, Zmasek CM (2009) phyloXML: XML for evolutionary biology and comparative genomics. BMC Bioinformatics 10(1):356 doi:10.1186/1471-2105-10-356

Kawai G, Babasaki K, Neda H (2008) Taxonomic position of a Chinese Pleurotus "Bai-Ling-Gu": it belongs to Pleurotus eryngii (DC.: Fr.) Quél. and evolved independently in China. Mycoscience 49(1):75-87 doi:http://dx.doi.org/10.1007/S10267-007-0392-2

Kuijk SJAv (2016) Fungal treatment of lignocellulosic biomass (Doctoral dissertation). Retrieved from http://edepot.wur.nl/370642.

Sonnenberg ASM, Gao W, Lavrijssen B, Hendrickx P, Sedaghat-Tellgerd N, Foulongne-Oriol M, Kong W-S, Schijlen EGWM, Baars JJP, Visser RGF (2016) A detailed analysis of the recombination landscape of the button mushroom Agaricus bisporus var. bisporus. Fungal Genetics and Biology 93:35-45

Sonnenberg ASM, Groot PWJd, Schaap PJ, Baars JJP, Visser J, Griensven LJLDv (1996) Isolation of expressed sequence tags of Agaricus bisporus and their assignment to chromosomes. Applied and Environmental Microbiolology 62:4542-4547

Terashima K, Matsumoto T, Hayashi E, Fukumasa-Nakai Y (2002) A genetic linkage map of Lentinula edodes (shiitake) based on AFLP markers* *Contribution No. 355 of The Tottori Mycological Institute. Mycological Research 106(8):911-917 doi:http://dx.doi.org/10.1017/S0953756202006275

Tuyen DV, Phuong HN, Cone JW, Baars JJP, Sonnenberg ASM, Hendriks WH (2013) Effect of fungal treatments of fibrous agricultural by-products on chemical composition and in vitro rumen fermentation and methane production. Bioresource Technology 129:256-263

Tuyen VD, Cone JW, Baars JJP, Sonnenberg ASM, Hendriks WH (2012) Fungal strain and incubation period affect chemical composition and nutrient availability of wheat straw for rumen fermentation. Bioresource Technology 111:336-342

Van Soest PJ, Robertson JB, Lewis BA (1991) Methods for Dietary Fiber, Neutral Detergent Fiber, and Nonstarch Polysaccharides in Relation to Animal Nutrition. Journal of Dairy Science 74(10):35833597 doi:http://dx.doi.org/10.3168/jds.S0022-0302(91)78551-2

Venturella G, Zervakis G, La Rocca S (2000) Pleurotus eryngii var. elaeoselini var. nov. from Sicily. Mycotaxon 77:19

Zervakis GI, Ntougias S, Gargano ML, Besi MI, Polemis E, Typas MA, Venturella G (2014) A reappraisal of the Pleurotus eryngii complex - New species and taxonomic combinations based on the application of a polyphasic approach, and an identification key to Pleurotus taxa associated with Apiaceae plants. Fungal biology 118(9-10):814-834 doi:http://dx.doi.org/10.1016/j.funbio.2014.07.001 


\section{Appendix}
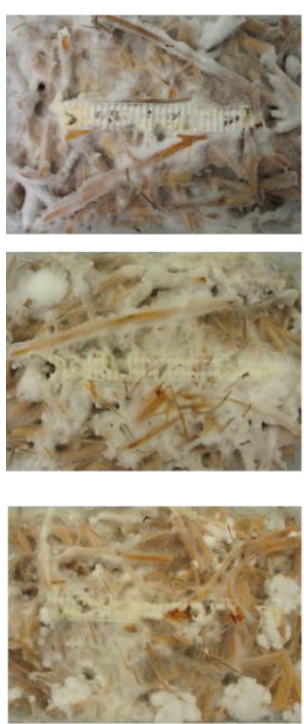

MES 12975
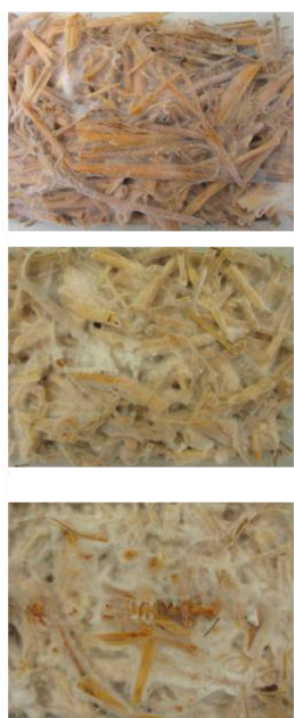

MES 03757
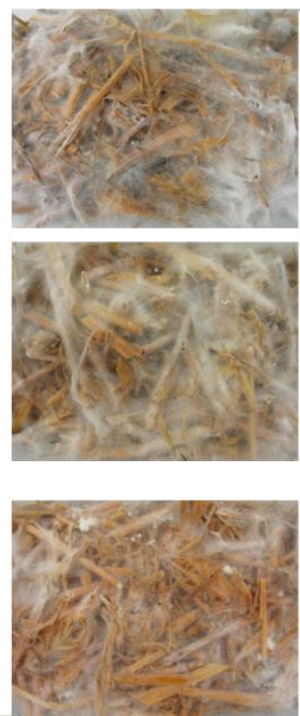

MES 11774
3 weeks

6 weeks

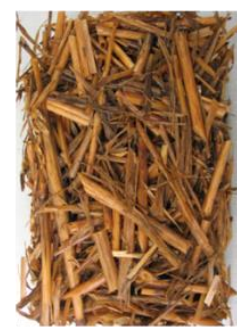

Control

Figure A1. Colonization of wheat straw by 3 different strains of $P$. eryngii on wheats straw. After 9 weeks of incubation strain MES12975 resulted in wheat straw with the lowest lignin content, MES 11774 the highest lignin content and MES 03757 showed an intermediate lignin content in wheat straw. 


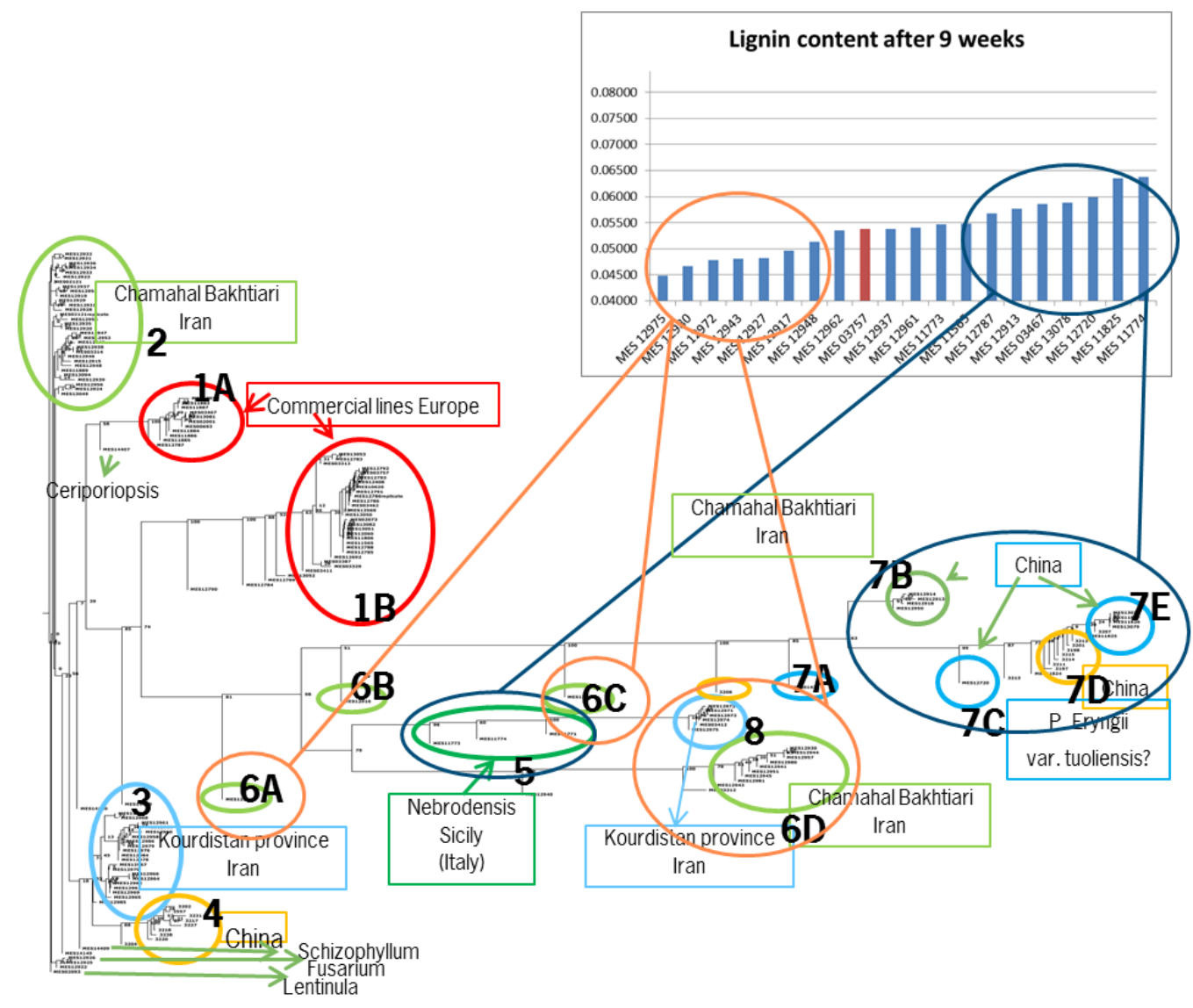

Figure 2A. The 6 strains in reducing lignin content in wheat straw after 9 weeks represent isolates from Iran and show a large genetic variation (orange circles). Strains with a low lignin reduction are nebrodensis and tuolienis varieties. These are strains that take long incubation time for colonisation of substrate and a cold shock before producing fruiting bodies. 


\begin{tabular}{|c|c|c|c|c|c|}
\hline Strain & $A D L$ & Strain & Hemicel. & Strain & Cellulose \\
\hline MES12975 & 0.04486 a & MES12917 & $0.1737 \mathrm{a}$ & MES13078 & $0.4903 \mathrm{a}$ \\
\hline MES12980 & $0.0467 \mathrm{ab}$ & MES12948 & $0.1775 a b$ & MES11825 & $0.4949 a b$ \\
\hline MES12972 & $0.04784 a b c$ & MES12962 & $0.1791 a b c$ & MES12913 & $0.4962 a b c$ \\
\hline MES12943 & $0.04805 \mathrm{abcd}$ & MES12980 & $0.1792 a b c$ & MES11773 & $0.4977 \mathrm{abcd}$ \\
\hline MES12927 & $0.04826 \mathrm{abcd}$ & MES12961 & $0.1813 a b c$ & MES11774 & $0.4979 \mathrm{abcd}$ \\
\hline MES12917 & 0.04963 abcde & MES12972 & $0.1815 a b c$ & MES12720 & $0.498 \mathrm{abcd}$ \\
\hline MES12948 & 0.05128 abcdef & MES12927 & $0.1836 \mathrm{abcd}$ & MES03467 & 0.5004 abcde \\
\hline MES12962 & 0.05358 abcdef & MES03757 & $0.1843 \mathrm{abcd}$ & MES03757 & 0.5051 abcdef \\
\hline MES03757 & 0.0538 abcdef & MES12937 & 0.1863 abcde & MES12961 & 0.5076 bcdef \\
\hline MES12937 & 0.05382 abcdef & MES12943 & 0.1876 abcde & MES11565 & 0.5084 bcdef \\
\hline MES12961 & 0.05407 abcdefg & MES12975 & 0.1896 abcdef & MES12962 & 0.5085 bcdef \\
\hline MES11773 & 0.05472 bcdefgh & MES11565 & 0.193 abcdef & MES12787 & 0.5088 bcdef \\
\hline MES11565 & 0.05484 bcdefgh & MES11773 & 0.2028 abcdefg & MES12980 & 0.5099 bcdef \\
\hline MES12787 & 0.0568 cdefgh & MES03467 & 0.2063 bcdefg & MES12917 & 0.5105 bcdef \\
\hline MES12913 & 0.05764 defgh & MES12787 & 0.2096 cdefg & MES12948 & 0.5109 bcdef \\
\hline MES03467 & 0.05857 efgh & MES11825 & 0.2127 defg & MES12943 & 0.5112 bcdef \\
\hline MES13078 & 0.05887 efgh & MES12720 & 0.2139 defg & MES12937 & 0.5119 cdef \\
\hline MES12720 & $0.05984 \mathrm{fgh}$ & MES12913 & $0.2164 \mathrm{efg}$ & MES12927 & 0.5131 def \\
\hline MES11825 & $0.06343 \mathrm{gh}$ & MES11774 & $0.2191 \mathrm{fg}$ & MES12972 & 0.5153 ef \\
\hline MES11774 & $0.0637 \mathrm{~h}$ & MES13078 & $0.2245 \mathrm{~g}$ & MES12975 & $0.519 \mathrm{f}$ \\
\hline
\end{tabular}

Table A1. Statistical analysis of fibre content. Each strain was incubated in duplicates.

Significance of differences are indicated for each fibre fraction in the third column: strains sharing same letters do not differ significantly.

\begin{tabular}{|c|c|c|c|c|c|c|c|c|c|c|c|c|c|}
\hline \multirow[b]{2}{*}{ Denrogram group } & \multirow[b]{2}{*}{ Strain } & \multicolumn{4}{|c|}{$A D L$} & \multicolumn{4}{|c|}{ Hemicellulose } & \multicolumn{4}{|c|}{ Cellulose } \\
\hline & & $\mathrm{T}=0$ & $T=3$ & $\mathrm{~T}=6$ & $T=9$ & $T=0$ & $\mathrm{~T}=3$ & $\mathrm{~T}=6$ & $T=9$ & $T=0$ & $T=3$ & $T=6$ & $\mathrm{~T}=9$ \\
\hline 8 & MES 12975 & 0.07720 & 0.07026 & 0.06169 & 0.04486 & 0.30653 & 0.24351 & 0.21932 & 0.18963 & 0.49587 & 0.49469 & 0.50182 & 0.51897 \\
\hline $6 \mathrm{D}$ & MES 12980 & 0.07720 & 0.07272 & 0.06100 & 0.04670 & 0.30653 & 0.24745 & 0.21698 & 0.17919 & 0.49587 & 0.49178 & 0.49799 & 0.50986 \\
\hline 8 & MES 12972 & 0.07720 & 0.07534 & 0.06189 & 0.04784 & 0.30653 & $3 \quad 0.25221$ & 0.21770 & 0.18148 & 0.49587 & 0.49260 & 0.49513 & 0.51529 \\
\hline $6 \mathrm{D}$ & MES 12943 & 0.07720 & 0.07541 & 0.06483 & 0.04805 & 0.30653 & $3 \quad 0.25013$ & 0.22141 & 0.18759 & 0.49587 & 0.48797 & 0.48963 & 0.51121 \\
\hline $6 \mathrm{~A}$ & MES 12927 & 0.07720 & 0.07152 & 0.05754 & 0.04826 & 0.30653 & 0.25965 & 0.23513 & 0.18361 & 0.49587 & 0.48653 & 0.49159 & 0.51308 \\
\hline $6 C$ & MES 12917 & 0.07720 & 0.07258 & 0.05835 & 0.04963 & 0.30653 & 0.25325 & 0.22259 & 0.17373 & 0.49587 & 0.49891 & 0.50658 & 0.51053 \\
\hline 2 & MES 12948 & 0.07720 & 0.07430 & 0.06007 & 0.05128 & 0.30653 & 0.24652 & 0.20785 & 0.17749 & 0.49587 & 0.49329 & 0.50220 & 0.51094 \\
\hline 3 & MES 12962 & 0.07720 & 0.07272 & 0.06552 & 0.05358 & 0.30653 & 0.24119 & 0.21868 & 0.17915 & 0.49587 & 0.50169 & 0.50352 & 0.50849 \\
\hline 1B & MES 03757 & 0.07720 & 0.07147 & 0.06218 & 0.05380 & 0.30653 & 0.24864 & 0.20668 & 0.18428 & 0.49587 & 0.49528 & 0.50361 & 0.50508 \\
\hline 2 & MES 12937 & 0.07720 & 0.07113 & 0.06488 & 0.05382 & 0.30653 & 0.24668 & 0.21165 & 0.18634 & 0.49587 & 0.49757 & 0.50801 & 0.51191 \\
\hline 3 & MES 12961 & 0.07720 & 0.07251 & 0.06345 & 0.05407 & 0.30653 & 0.25552 & 0.21565 & 0.18132 & 0.49587 & 0.49683 & 0.50326 & 0.50762 \\
\hline 5 & MES 11773 & 0.07720 & 0.07678 & 0.05901 & 0.05472 & 0.30653 & 0.25475 & 0.23255 & 0.20276 & 0.49587 & 0.48983 & 0.50509 & 0.49769 \\
\hline 1B & MES 11565 & 0.07720 & 0.07184 & 0.05679 & 0.05484 & 0.30653 & 0.25012 & 0.20610 & 0.19299 & 0.49587 & 0.49275 & 0.50303 & 0.50838 \\
\hline $1 \mathrm{~A}$ & MES 12787 & 0.07720 & 0.07533 & 0.07114 & 0.05680 & 0.30653 & 0.25496 & 0.23814 & 0.20964 & 0.49587 & 0.49810 & 0.50618 & 0.50881 \\
\hline $7 \mathrm{~B}$ & MES 12913 & 0.07720 & 0.07756 & 0.06977 & 0.05764 & 0.30653 & 0.26299 & 0.24114 & 0.21639 & 0.49587 & 0.48990 & 0.49470 & 0.49619 \\
\hline $1 \mathrm{~A}$ & MES 03467 & 0.07720 & 0.07794 & 0.05991 & 0.05857 & 0.30653 & 0.26341 & 0.22638 & 0.20634 & 0.49587 & 0.48520 & 0.50258 & 0.50038 \\
\hline $7 E$ & MES 13078 & 0.07720 & 0.07514 & 0.07588 & 0.05887 & 0.30653 & 0.26236 & 0.24641 & 0.22455 & 0.49587 & 0.50059 & 0.48613 & 0.49025 \\
\hline 7C & MES 12720 & 0.07720 & 0.08172 & 0.06995 & 0.05984 & 0.30653 & 0.25150 & 0.23918 & 0.21386 & 0.49587 & 0.49815 & 0.50072 & 0.49796 \\
\hline $7 \mathrm{E}$ & MES 11825 & 0.07720 & 0.07899 & 0.07535 & 0.06343 & 0.30653 & 0.25917 & 0.24054 & 0.21273 & 0.49587 & 0.49505 & 0.48292 & 0.49488 \\
\hline 5 & MES 11774 & 0.07720 & 0.07899 & 0.06944 & 0.06370 & 0.30653 & 0.25917 & 0.25403 & 0.21909 & 0.49587 & 0.49505 & 0.50570 & 0.49791 \\
\hline
\end{tabular}

Table A1. Fibre analysis of wheat straw samples after treatment with different strains of $P$. eryngii.

Data represent percentage of each fraction of the dry weight of wheat straw. Hemicellulose is

expressed as NDF-ADF and cellulose as ADF-ADL. 


\begin{tabular}{|c|c|c|}
\hline untreated & 210 & \\
\hline & Mean & \\
\hline MES 13078 & 208.2 & $a$ \\
\hline MES 11825 & 213.2 & $a b$ \\
\hline MES 12720 & 225.5 & $a b c$ \\
\hline MES 12913 & 238.6 & $a b c d$ \\
\hline MES 12943 & 240.4 & abcd \\
\hline MES 03467 & 243 & bcd \\
\hline MES 11774 & 246.2 & bcd \\
\hline MES 03757 & 246.5 & $c d$ \\
\hline MES 12917 & 250.2 & $\mathrm{~cd}$ \\
\hline MES 12787 & 251.6 & $c d$ \\
\hline MES 12961 & 253.9 & $\mathrm{~cd}$ \\
\hline MES 12980 & 259.6 & $\mathrm{~cd}$ \\
\hline MES 12937 & 260.2 & $c d$ \\
\hline MES 11565 & 261.5 & $\mathrm{~cd}$ \\
\hline MES 12962 & 262.5 & $\mathrm{~cd}$ \\
\hline MES 11773 & 263.3 & $\mathrm{~cd}$ \\
\hline MES 12948 & 263.6 & $c d$ \\
\hline MES 12975 & 264.1 & $c d$ \\
\hline MES 12972 & 267.9 & $d$ \\
\hline MES 12927 & 270.4 & $d$ \\
\hline
\end{tabular}

Table A2. Statistical analysis of IVGP ("Mean" after 9 weeks of incubation) in the model by different $P$. eryngii strains (MES numbers). Due to a large variation in duplicates, most treatments do not vary significantly. 
Corresponding address for this report:

P.O. Box 16

6700 AA Wageningen

The Netherlands

T +31 (0)317480700

www.wageningenUR.nl/en/XX

Confidential PPO/PRI report 2015-6
Plant researchers of Wageningen UR aim to utilise plant properties to help solve issues concerning food, raw materials and energy. They are devoting their knowledge of plants and their up-to-date facilities to increasing the innovative capacity of our clients. In doing so, they work on improving the quality of life.

The mission of Wageningen UR (University \& Research centre) is 'To explore the potential of nature to improve the quality of life'. Within Wageningen UR, nine specialised research institutes of the DLO Foundation have joined forces with Wageningen University to help answer the most important questions in the domain of healthy food and living environment. With approximately 30 locations, 6,000 members of staff and 10,000 students, Wageningen UR is one of the leading organisations in its domain worldwide. The integral approach to problems and the cooperation between the various disciplines are at the heart of the unique Wageningen Approach. 